OPEN ACCESS

Edited by:

John Stambas,

Deakin University, Australia

Reviewed by:

Stephen Kent,

The University of Melbourne, Australia

Marie-Lise Gougeon,

Institut Pasteur, France

*Correspondence:

Anke Huckriede

a.l.w.huckriede@umcg.n

${ }^{\dagger}$ Present Address: Kate Guilfoyle,

Viroclinics Biosciences B.V.,

Rotterdam, Netherlands

Specialty section: This article was submitted to

Viral Immunology,

a section of the journa

Frontiers in Immunology

Received: 13 July 2018 Accepted: 17 September 2018 Published: 09 October 2018

Citation:

Dong W, Bhide Y, Sicca F, Meijerhof T,

Guilfoyle K, Engelhardt OG, Boon L,

de Haan CAM, Carnell G,

Temperton N, de Vries-Idema J,

Kelvin D and Huckriede A (2018)

Cross-Protective Immune Responses Induced by Sequential Influenza Virus Infection and by Sequential

Vaccination With Inactivated Influenza

Vaccines. Front. Immunol. 9:2312.

doi: 10.3389/fimmu.2018.02312

\section{Cross-Protective Immune Responses Induced by Sequential Influenza Virus Infection and by Sequential Vaccination With Inactivated Influenza Vaccines}

\author{
Wei Dong ${ }^{1,2}$, Yoshita Bhide ${ }^{1}$, Federica Sicca ${ }^{1}$, Tjarko Meijerhof ${ }^{1}$, Kate Guilfoyle ${ }^{3+}$, \\ Othmar G. Engelhardt ${ }^{3}$, Louis Boon ${ }^{4}$, Cornelis A. M. de Haan ${ }^{5}$, George Carnell ${ }^{6}$, \\ Nigel Temperton ${ }^{6}$, Jacqueline de Vries-Idema ${ }^{1}$, David Kelvin ${ }^{2,7}$ and Anke Huckriede ${ }^{1 *}$ \\ ${ }^{1}$ Department of Medical Microbiology, University of Groningen, University Medical Center Groningen, Groningen, \\ Netherlands, ${ }^{2}$ Division of Immunology, International Institute of Infection and Immunity, Shantou University Medical College, \\ Shantou, China, ${ }^{3}$ National Institute for Biological Standards and Controls, Medicines and Healthcare Products Regulatory \\ Agency, Potters Bar, United Kingdom, ${ }^{4}$ Bioceros, Utrecht, Netherlands, ${ }^{5}$ Virology Division, Department of Infectious \\ Diseases \& Immunology, Faculty of Veterinary Medicine, Utrecht University, Utrecht, Netherlands, ${ }^{6}$ Viral Pseudotype Unit, \\ Medway School of Pharmacy, University of Kent, Chatham Maritime, Kent, United Kingdom, ${ }^{7}$ Department of Microbiology \\ and Immunology, Dalhousie University, Halifax, NS, Canada
}

Sequential infection with antigenically distinct influenza viruses induces cross-protective immune responses against heterologous virus strains in animal models. Here we investigated whether sequential immunization with antigenically distinct influenza vaccines can also provide cross-protection. To this end, we compared immune responses and protective potential against challenge with $A(H 1 N 1) p d m 09$ in mice infected sequentially with seasonal $\mathrm{A}(\mathrm{H} 1 \mathrm{~N} 1)$ virus followed by $\mathrm{A}(\mathrm{H} 3 \mathrm{~N} 2)$ virus or immunized sequentially with whole inactivated virus (WIV) or subunit (SU) vaccine derived from these viruses. Sequential infection provided solid cross-protection against $A(H 1 N 1) p d m 09$ infection while sequential vaccination with WIV, though not capable of preventing weight loss upon infection completely, protected the mice from reaching the humane endpoint. In contrast, sequential SU vaccination did not prevent rapid and extensive weight loss. Protection correlated with levels of cross-reactive but non-neutralizing antibodies of the IgG2a subclass, general increase of memory $T$ cells and induction of influenza-specific CD4+ and CD8+ T cells. Adoptive serum transfer experiments revealed that despite lacking neutralizing activity, serum antibodies induced by sequential infection protected mice from weight loss and vigorous virus growth in the lungs upon $A(H 1 N 1) p d m 09$ virus challenge. Antibodies induced by WIV vaccination alleviated symptoms but could not control virus growth in the lung. Depletion of T cells prior to challenge revealed that CD8+ T cells, but not CD4+ T cells, contributed to cross-protection. These results imply that sequential immunization with WIV but not SU derived from antigenically distinct viruses could alleviate the severity of infection caused by a pandemic and may improve protection to unpredictable seasonal infection.

Keywords: sequential vaccination, cross-protection, antigenically distinct influenza virus strains, immune mechanism, non-neutralizing antibody 


\section{INTRODUCTION}

Influenza A virus (IAV) infections remain a worldwide public health threat. Influenza vaccination is the most reliable strategy to control annual epidemics and irregular pandemics (1). Current inactivated influenza vaccines (IIV) primarily induce strain-specific antibodies against the two major virus surface proteins, hemagglutinin (HA) and neuraminidase (NA). However, these strain-specific antibodies cannot provide protection against antigenically drifted and antigenically shifted strains. When a pandemic strain emerges, it takes around 6 months to develop and distribute a new vaccine (2), which is too late for a vaccine to provide effective protection during the first pandemic wave. Thus, a cross-protective vaccine that could provide immediate protection against unpredicted influenza virus strains is urgently needed.

Live virus infection has been shown to provide some degree of cross-protection against $\mathrm{A}(\mathrm{H} 1 \mathrm{~N} 1)$ pdm09 infection in animal models (3-8) and in humans $(9,10)$. However, the exact mechanisms involved in cross-protection remain elusive. Cross-reactive antibodies against conserved regions of viral proteins, such as the HA stalk, the M2 ectodomain (M2e) and nucleoprotein (NP), induced by (sequential) live virus infection, correlate with cross-protection $(3,11-13)$. Some anti-HA stalk antibodies can directly neutralize influenza virus particles in vitro (14). However, most of these antibodies target antigens that are expressed on the surface of infected cells and then provide crossprotection via a Fc receptor dependent mechanism (14-16).

Besides antibody responses, cross-reactive $\mathrm{T}$ cells induced by live virus infection have also been demonstrated to correlate with cross-protection $(5,6,17)$. Cytotoxic CD8 T cells can recognize internal, conserved epitopes across different virus strains. In animal models, CD8 T cells induced by live virus infection have been shown to prevent $\mathrm{A}(\mathrm{H} 5 \mathrm{~N} 1)$ or $\mathrm{A}(\mathrm{H} 1 \mathrm{~N} 1) \mathrm{pdm} 09$ virus infection (18). On the other hand, CD4 T cells specific for conserved epitopes have also been shown to provide protection against $\mathrm{A}(\mathrm{H} 1 \mathrm{~N} 1) \mathrm{pdm} 09$ in mice $(19,20)$. These CD4 T cells could provide cross-protection through different mechanisms, including help for B cells, help for CD8 T cells and direct cytotoxic activity [reviewed in (21)]. Furthermore, it has been demonstrated in humans that the presence of memory cross-reactive CD4 or CD8 T cells is correlated with crossprotection against $\mathrm{A}(\mathrm{H} 1 \mathrm{~N} 1) \mathrm{pdm} 09$ or $\mathrm{A}(\mathrm{H} 7 \mathrm{~N} 9)$ virus infection $(9,22,23)$.

Vaccination with trivalent inactivated influenza vaccine (IIV) did not provide protection against $\mathrm{A}(\mathrm{H} 1 \mathrm{~N} 1) \mathrm{pdm} 09$ virus infection and was even found to be associated with enhanced disease in observational studies from Canada in humans (2428). In animal models, published studies indicate that vaccination with IIV could induce detectable levels of cross-reactive antibody against $\mathrm{A}(\mathrm{H} 1 \mathrm{~N} 1)$ pdm09 virus, yet, no cross-protection was observed (29-31). The exception is a recent study showing that non-neutralizing antibody induced by IIV could cause activation of influenza-specific CD8 T cells by promoting antigen presentation (32). If a broader immune response could be induced by the currently available influenza vaccines, it would benefit humans against novel virus infection.
Compared with a single virus infection, sequential infection with antigenically distinct live viruses was found to provide broader cross-protection $(7,8,11)$. This is because the second infection can cause a quick recall immune response to epitopes shared between the two viruses. It has been shown that sequential influenza virus infection can boost antibody responses to the shared HA stalk region $(11,33)$.

Sequential immunization with antigenically distinct vaccines has also been used as a strategy to induce a broader immune response against influenza virus in animal models (34). However, most of these studies were focused on the cross-protective immune response induced by genetically modified vaccines (3538). Little is known about the protective potential of sequential immunization with conventional inactivated vaccines derived from different seasonal influenza virus strains. In case of a pandemic, such a vaccination strategy could be a first means of intervention until a pandemic vaccine becomes available.

In this study, we assessed the cross-protective immune responses induced by sequential infection with $\mathrm{A}(\mathrm{H} 1 \mathrm{~N} 1)$ and $\mathrm{A}(\mathrm{H} 3 \mathrm{~N} 2)$ virus, or sequential immunization with whole inactivated virus (WIV) or subunit (SU) vaccine derived from these viruses in a mouse model. Sequential infection provided robust cross-protection which was mediated by non-neutralizing, cross-reactive antibody and CD8 effector memory T cells (TEM). Partial cross-protection was provided by sequential vaccination with WIV and was associated with CD8 central memory T cells (TCM), and to a minor extent, with cross-reactive antibodies. In contrast, sequential vaccination with $\mathrm{SU}$ vaccine induced low levels of cross-reactive serum antibodies and no T cell immunity against $\mathrm{A}(\mathrm{H} 1 \mathrm{~N} 1) \mathrm{pdm} 09$, and did not provide cross-protection. These results imply that in case of a new pandemic, sequential immunization with WIV but not subunit vaccines derived from different seasonal virus strains could mitigate disease severity until a pandemic vaccine becomes available.

\section{MATERIALS AND METHODS}

\section{Virus and Vaccines}

Influenza virus strains A/Puerto Rico/8/34 (H1N1)(PR8), $\mathrm{X}-31$, a reassortant virus derived from A/Aichi/2/68 (H3N2), A/California/07/09 (H1N1)pdm09, and X-181 (a reassortant derived from (H1N1)pdm09 and PR8) were grown in embryonated chicken eggs, and the virus preparations were titrated on MDCK cells and in mice. Whole inactivated virus vaccines was produced from PR8, X31 and X-181 by treatment with $\beta$-propiolactone. PR8 SU and X-31 SU were prepared from PR8 and X-31 WIV, respectively, as described before (39).

\section{Vaccination, Challenge, and Sample Collection}

Female 6-8 weeks old CB6F1 mice were purchased from Envigo, The Netherlands, and rested for at least 1 week. Mice were housed under SPF conditions in standard polycarbonate cages (5 animals per cage) with standard rodent bedding and cardboard cylinders as cage enrichment. Prior to the start of the experiment, animals were randomly allocated to the different treatment groups. All animal experiments were approved by the Central 
Committee for Animal Experiments CCD of the Netherlands (AVD105002016599). All experimental protocols were approved by the Animal Ethics Committee of the University Medical Center Groningen. Group sizes were determined using Piface software such that a power of at least $80 \%$ was reached.

Naive mice $(n=15)$ were immunized intramuscularly (i.m.) with $15 \mu \mathrm{g}$ of PR8 WIV (containing around $5 \mu \mathrm{g}$ of HA) or 5 $\mu \mathrm{g}$ of PR8 SU vaccine. Alternatively, mice were anesthetized and infected intranasally (i.n.) with a sublethal dose $\left(10^{3} \mathrm{TCID}_{50}\right)$ of PR8 virus (live virus $=\mathrm{LV}$ ). Four weeks after immunization or infection, mice were i.m. immunized with $15 \mu \mathrm{g}$ of X-31 WIV or $5 \mu \mathrm{g}$ of X-31 SU or i.n. infected with a sublethal dose of $\left(10^{3}\right.$ TCID $\left._{50}\right)$ X-31 virus. Mice injected twice with PBS i.m. with 28 days interval served as negative control (Table 1).

Four weeks after the second infection or immunization, 5 mice of each group were sacrificed for determination of infectionor vaccine-induced immune responses. The other 10 mice were anesthetized with isoflurane and challenged i.n. with $10^{4.4}$ TCID50 of A/California/7/09 (H1N1)pdm09 in $40 \mu 1$ PBS. Three days post infection, 5 mice were sacrificed for determination of immune responses and lung virus titers. The remaining 5 mice were monitored daily for body weight loss for 2 weeks. Body weight loss exceeding 20\% was considered as humane endpoint.

On day 0 (before challenge) and day 3 post challenge, mice ( $n=5$ from each group) were sacrificed under isoflurane anesthesia. Serum, nose wash and bronchoalveolar lavage (BAL) were collected for further analysis. Lungs were perfused with $20 \mathrm{ml}$ PBS containing $0.1 \%$ heparin through the right heart ventricle. Right lung lobes were collected, homogenized, snapfrozen and stored at $-80^{\circ} \mathrm{C}$ for virus titration. The whole lung (day 0 ) or the left lung lobes (day 3 ) and the spleens were collected for lymphocyte isolation.

\section{Viral Titer in Lung}

Lung tissue collected on day 3 post-challenge was weighed, homogenized in $1 \mathrm{ml}$ of Episerf medium (Thermo Fisher Scientific) and then centrifuged at $1,200 \mathrm{rpm}$ for $10 \mathrm{~min}$. Supernatants were collected, aliquoted, snap-frozen and stored at $-80^{\circ} \mathrm{C}$ until use. Lung virus titers were determined by infection of MDCK cells in 96-well plates with serial dilutions of the lung supernatants as described before (39). Viral titers, presented as $\log 10$ titer of $50 \%$ tissue culture infectious dose per gram lung $\left(\log _{10} \mathrm{TCID}_{50} / \mathrm{g}\right)$, were calculated based on the Reed-Muench method (40).

TABLE 1 | Experimental design for mouse experiment

\begin{tabular}{llll}
\hline Groups & $\begin{array}{l}\text { First immunization } \\
\text { (Day 0) }\end{array}$ & $\begin{array}{l}\text { Second immunization } \\
\text { (Day 28) }\end{array}$ & $\begin{array}{l}\text { Challenge } \\
\text { (D56) }\end{array}$ \\
\hline 1 & PR8 WIV & X-31 WIV & H1N1pdm09 \\
2 & PR8 SU & X-31 SU & H1N1pdm09 \\
3 & PR8 LV* & X-31 LV & H1N1pdm09 \\
4 & PBS & PBS & H1N1pdm09 \\
\hline
\end{tabular}

${ }^{*} L V=$ live virus

\section{Isolation of Lymphocytes From Lung and Spleen}

Spleens were homogenized in complete IMDM (with 10\% FBS, $1 \%$ Penicillin-Streptomycin and $0.1 \% \beta$-mercaptoethanol) using a GentleMACS dissociator (Miltenyi Biotec B, Leiden, The Netherlands). Cell suspensions were then forced through a cell strainer (BD Bioscience, Breda, The Netherlands) and treated with ACK lysis buffer $\left(0.15 \mathrm{M} \mathrm{NH}_{4} \mathrm{Cl}, 10 \mathrm{mM} \mathrm{KHCO}_{3}, 0.1 \mathrm{mM}\right.$ EDTA, pH 7.2) to remove erythrocytes.

PBS-perfused lungs for isolation of lymphocytes were homogenized using a GentleMACS dissociator (Miltenyi Biotec) and then digested by treatment with collagenase D (0.5 mg/lung) (Roche, Woerden, The Netherlands) in DMEM medium supplemented with $2 \% \mathrm{FBS}$ at $37^{\circ} \mathrm{C}$ for $1.5 \mathrm{~h}$. The cell suspension was passed through a cell strainer. Lung lymphocytes in the filtered suspensions were enriched using lymphocyte density gradients (Sanbio, Uden, The Netherlands) according to the manufacturer's protocol.

\section{Elisa}

For the detection of IgG, IgG1, IgG2a, or IgA antibody against $\mathrm{A}(\mathrm{H} 1 \mathrm{~N} 1) \mathrm{pdm} 09$ virus in serum and nasal wash, ELISA plates (Greiner, Alphen a/d Rijn, Netherlands) were coated with $0.3 \mu \mathrm{g} /$ well of X-181 WIV, conserved M2e peptide (SLLTEVETPIRNEWGSRSNDSSD) or NP protein overnight at $37^{\circ} \mathrm{C}$ and ELISA assays were performed as described before (39). For NA-specific ELISA, recombinant NA protein of $\mathrm{A}(\mathrm{H} 1 \mathrm{~N} 1)$ pdm09 was expressed and purified as described previously (41). ELISA plates were coated with $0.1 \mu \mathrm{g} /$ well of NA overnight at $4{ }^{\circ} \mathrm{C}$ and assays were performed as described (39).

\section{Pseudotype HA Stalk Neutralization Assay}

Pseudotyped viruses (PV) were produced by co-transfection of HEK293T/17 cells using the polyethylenimine transfection reagent (Sigma, cat: 408727). Lentiviral packaging plasmid p8.91 and vector pCSFLW bearing the luciferase reporter were transfected alongside the relevant HA glycoprotein genes in the plasmid pI.18 (42). Parental PV were produced bearing the $\mathrm{HA}$ of A/California/7/09 (H1), or A/duck/Memphis/546/1974 (H11). A chimeric HA (cHA) consisting of the stalk from A/California/7/09 (H1) and head from A/duck/Memphis/546/1974 (H11) was also produced (43). Pseudotype based microneutralisation assays ( $\mathrm{pMN}$ ) were performed as described previously (42). Briefly, serial dilutions of serum were incubated with $1 \times 10^{6}$ relative luminescence units (RLU) of HA bearing PV per well on a 96-well white plate for $1 \mathrm{~h}$ at $37^{\circ} \mathrm{C} 5 \% \mathrm{CO}_{2}$ in a humidified incubator. $1.5 \times 10^{4}$ HEK293T/17 cells were then added per well and plates incubated at $37^{\circ} \mathrm{C} 5 \% \mathrm{CO}_{2}$ for $48 \mathrm{~h}$ before addition of Bright-Glo ${ }^{\mathrm{TM}}$ reagent (Promega) and measurement of luciferase activity. Analysis was performed using Graph-Pad Prism. Stalk-directed antibody presence was measured via antibody titers recorded against the cHA and both of its parental strains (H11 and H1 PV). No (or negligible) antibodies should be present against the exotic $\mathrm{H} 11 \mathrm{HA}$, restricting neutralization of the cHA PV to antibodies directed against the conserved $\mathrm{H} 1$ stalk of the cHA. Control antibodies used included mAb CR6261 (Crucell, Johnson, 
and Johnson) and polyclonal antiserum Anti H11N9 World Organization for Animal Health (OIE).

\section{Intracellular Cytokine Staining}

For IFN $\gamma$ intracellular cytokine staining, lymphocytes (1.5$2 \times 10^{6}$ ) from lung or spleen in complete IMDM medium were stimulated with anti-CD28 $(1 \mu \mathrm{g} / \mathrm{ml}$, eBioscience), with or without X-181 WIV $(10 \mu \mathrm{g} / \mathrm{ml})$, overnight at $37^{\circ} \mathrm{C}$ in a $5 \%$ $\mathrm{CO}_{2}$ incubator. Protein transport inhibitor cocktail (eBioscience) was added for the last $4 \mathrm{~h}$ of stimulation. Stimulated cells were stained with fluorochrome conjugated antibodies, including Alexa Fluor 700-antiCD3 (clone 17A2), FITC-antiCD4 (GK1.5), PerCP-cy5.5-antiCD8 $\alpha$ (53-6.7), eFlour 450-antiCD62L (MEL14), APC-antiCD44 (IM7) for $45 \mathrm{~min}$. After surface staining, cells were stained with Fixable Viability Dye eFluor 780 (eBioscience) to identify dead cells. Cells were then fixed with IC fixation buffer (eBioscience) and permeabilized with permeabilization buffer (eBioscience) before intracellular staining with PE-cy7-antiIFN $\gamma$ (clone XMG1.2) (all monoclonal antibodies from eBioscience). Samples were acquired on a BD LSRII and data were analyzed by Kaluza $^{\circledR}$ Flow Cytometry Analysis Software.

\section{Elispot and Tetramer Staining}

Influenza NP-specific IFN $\gamma$-producing $\mathrm{T}$ cells were enumerated using a commercial mouse IFN $\gamma$ ELISpot kit (MABTEC, The Netherlands) according to the manufacturer's protocol. Briefly, splenocytes $\left(2.5 \times 10^{5} /\right.$ well $)$ collected on day 0 post-infection were incubated with or without $5 \mu \mathrm{g} / \mathrm{ml}$ of the PR8 NP $366-374$ epitope (ASNENMDAM) in a pre-coated 96-well plate. After overnight incubation, IFN $\gamma$-producing $\mathrm{T}$ cells were detected using alkaline phosphatase-conjugated anti-mouse IFN $\gamma$ antibody. Spots were developed with BCIP/NBT substrate and counted with an AID Elispot reader (Autoimmune Diagnostika $\mathrm{GmbH}$, Strassberg, Germany). The number of antigen-specific IFN $\gamma$-producing cells was calculated by subtracting the number of spots detected in the unstimulated samples from the number in stimulated samples.

Tetramer staining for lung samples was performed as follows: isolated lung lymphocytes were incubated with $\mathrm{A}(\mathrm{H} 1 \mathrm{~N} 1) \mathrm{pdm} 09$ $\mathrm{NP}_{366-374}$-tetramer-PE (containing the $\mathrm{A}(\mathrm{H} 1 \mathrm{N1}$ )pdm09 epitope ASNENMETM) for $40 \mathrm{~min}$ and then stained with mouse antiCD8 $\alpha$-PerCP-cy5.5 antibody for $40 \mathrm{~min}$. Samples were acquired on a FACS Calibur ${ }^{\mathrm{TM}}$ BD II flow cytometer. Data were analyzed by Kaluza ${ }^{\circledR}$ Flow Cytometry Analysis Software.

\section{Serum Adoptive Transfer}

Mice were sequentially infected or sequentially immunized with WIV as described above and serum was collected on day 28 post second infection or immunization. Serum collected from mice that were immunized twice i.m. with A(H1N1)pdm09 WIV served as positive control. Pooled serum was tested by ELISA for presence of anti-A(H1N1)pdm09 antibodies. Naive mice ( $n=5$ /group) received $200 \mu$ l of pooled serum by intraperitoneal injection 1 day before challenge with $\mathrm{A}(\mathrm{H} 1 \mathrm{~N} 1) \mathrm{pdm} 09$ virus. On day 6 post challenge, lungs were collected for virus titration.

\section{CD4 and CD8 T Cell Depletion in vivo}

For the $\mathrm{T}$ cell depletion study, mice were infected or vaccinated as described above and rested for 28 days. Groups of mice ( $n=6$ /group) were injected with anti-CD4T cell depletion antibody (200 $\mu \mathrm{g} /$ injection, GK1.5) or anti-CD8 T cell (200 $\mu \mathrm{g} /$ injection, YTS169). These antibodies were given i.p on day $-1,1$, and 3 of $\mathrm{A}(\mathrm{H} 1 \mathrm{~N} 1)$ pdm09 virus $\left(10^{4.4} \mathrm{TCID}_{50}\right)$ challenge. On day 6 post challenge, lungs were collected for virus titration. Spleens were collected to confirm the depletion of T cells.

\section{Statistics}

Mann-Whitney $U$-test was used to determine the differences between read-outs of two different groups. Statistical analyses were performed using GraphPad Prism version 6.01 for Windows. GraphPad Sofware, La Jolla, California, USA www. graphpad.com. $P<0.05,0.01,0.001$ were considered as significantly different and were denoted by $*, * *, * * *$, individually.

\section{RESULTS}

\section{Sequential Infection, WIV and SU Vaccination Show Different Levels of Cross-Protective Capacity Against H1N1pdm09 Influenza Virus Infection}

To investigate the cross-protective immune response induced by sequential infection or vaccination with antigens from different influenza virus strains, we sequentially infected mice with PR8 and X-31 influenza virus or sequentially vaccinated mice with WIV or SU vaccines derived from these viruses. These viral strains were selected to reflect a heterosubtypic exposure history in humans. The cross-protective capacity of sequential infection or sequential immunization was determined by challenging the mice with virus A/California/7/09 (H1N1)pdm09.

After $\mathrm{A}(\mathrm{H} 1 \mathrm{~N} 1)$ pdm09 virus challenge, mice in the sequential $\mathrm{SU}$ vaccination group showed similar weight loss as mice in the PBS control group and developed severe symptoms, necessitating euthanasia on day 6 or 7 post challenge (Figures 1A,B). Mice that were sequentially vaccinated with WIV showed a similar trend of weight loss as mice in the PBS control group until day 6 post infection. Yet, from day 7 post infection onwards, WIV immunized mice recovered and none of the mice reached the humane endpoint. In the sequential infection group, mice showed no or only minor weight loss after challenge and none of them needed to be sacrificed.

On day 3 post-challenge, lung virus titers in the sequential $\mathrm{SU}$ vaccination group did not differ significantly from those in the PBS control group (Figure 1C). In the sequential WIV vaccination group, lung virus titers were decreased by $0.9 \log _{10}$ as compared to the PBS group $(p=0.03)$. Sequential infection resulted in a significant decrease of the lung virus titer by $2 \log _{10}$ relative to the control group ( $p=0.015$ ).

These data demonstrate that sequential immunization with WIV, although being less effective than sequential infection with live virus, provided a certain level of cross-protection against heterologous infection. In contrast, sequential SU vaccination did not provide cross-protection. 

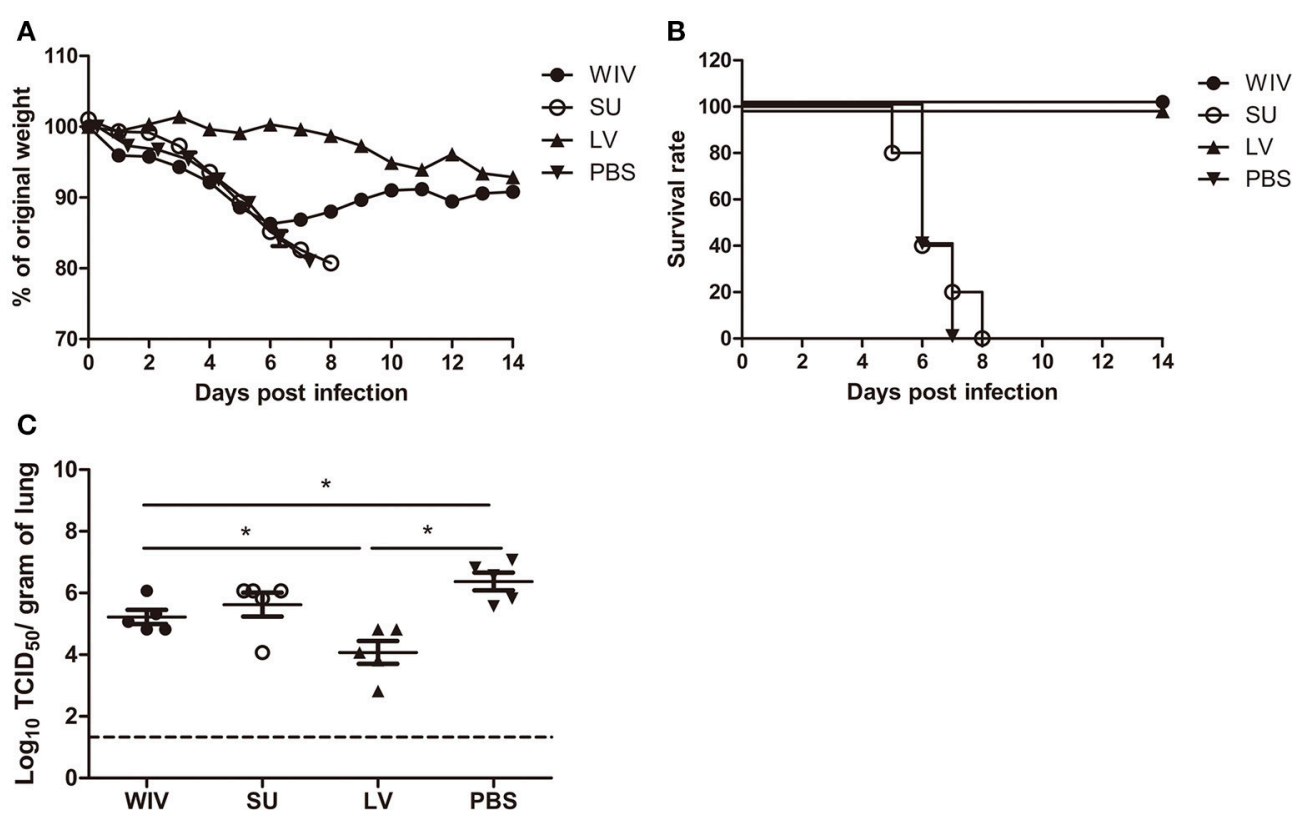

FIGURE 1 | Weight loss, survival rate, and lung virus titer of immunized mice after A(H1N1)pdm09 virus challenge. Naïve mice ( $n=10)$ were sequentially infected with sublethal doses of two different strains (PR8 and then X31) of live virus (LV) with 28 days interval or were sequentially immunized with vaccines (WIV, SU) derived from these virus strains and then challenged with virus A/California/7/2009 (H1N1)pdm09. After challenge, mice $(n=5)$ were monitored daily for weight loss (A) and survival (B) for a period of 14 days. On day 3 post-challenge, lung virus titers in 5 mice/group were determined by titration on MDCK cells (C). ${ }^{*} p<0.05$, Mann-Whitney $U$-test. The dashed line represents the limit of detection.

\section{Sequential Infection, WIV and SU Vaccination Induce Distinct Cross-Reactive Antibody Responses}

To explore the immune mechanisms involved in protection from weight loss and lung virus growth upon challenge, antibody responses induced by sequential infection with PR8 and X-31 or immunization with PR8 and X-31 derived vaccines were determined.

A single infection with PR8 or immunization with PR8derived vaccines raised antibodies recognizing PR8 surface proteins in all animals. Although the dose of WIV and SU vaccines was chosen such that both contained the same amount of surface antigens, a single immunization with WIV induced around 30 times more PR8 HA/NA specific IgG than a single immunization with SU $(p<0.0001)$ (Figure 2A). Antibody titers raised by a sublethal infection were significantly higher than those raised by WIV $(p<0.01)$ but the difference was only 1.7-fold. Upon subsequent immunization/infection with X-31, on day 56, antibody titers to X-31 HA/NA in WIV-immunized mice were approximately 10 -fold higher than in SU-immunized mice and around 3-fold higher than in sequentially infected mice $(p<0.0001)$ (Figure 2B).

On day 56, after sequential exposure to PR8 and X-31, we also determined antibody titers against heterologous $\mathrm{A}(\mathrm{H} 1 \mathrm{~N} 1) \mathrm{pdm} 09$ virus. Sequential infection induced around 20 times more crossreactive IgG antibody than sequential WIV vaccination and approximately 75 times more than sequential SU vaccination $(p<0.0001)$ (Figure 2C). With respect to the subtype profile of the IgG antibodies, sequential infection and WIV vaccination induced a Th1-type antibody response. The average ratio of serum IgG2a to IgG1 concentration was 3 for mice sequentially infected by live virus, compared with 1.5 induced by sequential WIV vaccination. In contrast, sequential SU vaccination induced a similar amount of IgG1 antibody as induced by sequential WIV vaccination but no IgG2a (Figure 2D). However, crossreactive antibodies, irrespective of whether induced by sequential infection or immunization, did not neutralize $\mathrm{A}(\mathrm{H} 1 \mathrm{~N} 1) \mathrm{pdm} 09$ virus (Figure 2E). With respect to mucosal antibodies, only sequential infection was found to induce cross-reactive $\operatorname{IgA}$ antibody against $\mathrm{A}(\mathrm{H} 1 \mathrm{~N} 1) \mathrm{pdm} 09$ virus in the nose (Figure 2F).

In order to reveal the target protein(s) of the observed crossreactive antibodies we first performed a pseudovirus-based assay to detect antibodies to the HA stalk domain. This assay uses a chimeric HA as antigen, with an H11 globular head, and an H1 stalk. The chimeric HA pseudovirus particles were effectively neutralized by the CR6261 mAb control which binds to the $\mathrm{H} 1$ stalk. However, no or very low amounts of antibodies reacting with the $\mathrm{H} 1$ stalk were observed in any of the experimental groups (Figure S1A). Next, we examined anti-NA antibodies against $\mathrm{A}(\mathrm{H} 1 \mathrm{~N} 1)$ pdm09 virus. The mice from the sequential infection group and 4 out of 5 mice from the WIV vaccination group developed anti-NA antibodies, while only 2 out of 5 mice from the sequential SU vaccination group did so and levels of anti-NA antibody were low (Figure S1B). Next, antiM2e antibody titers were determined by coating conserved M2e peptide onto 96-well ELISA plate. Anti-M2e antibodies were only found in the sequential infection group (Figure S1C). We 


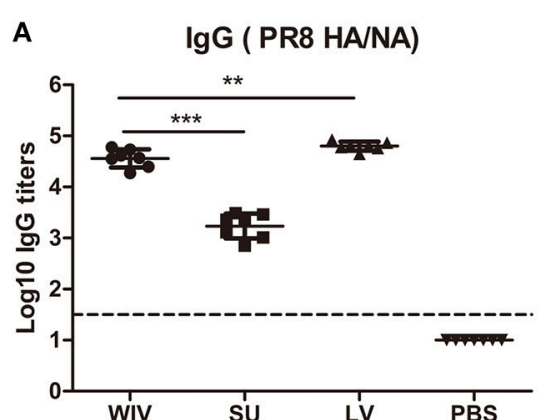

B $\quad \lg (\mathrm{X}-31 \mathrm{HA} / \mathrm{NA})$
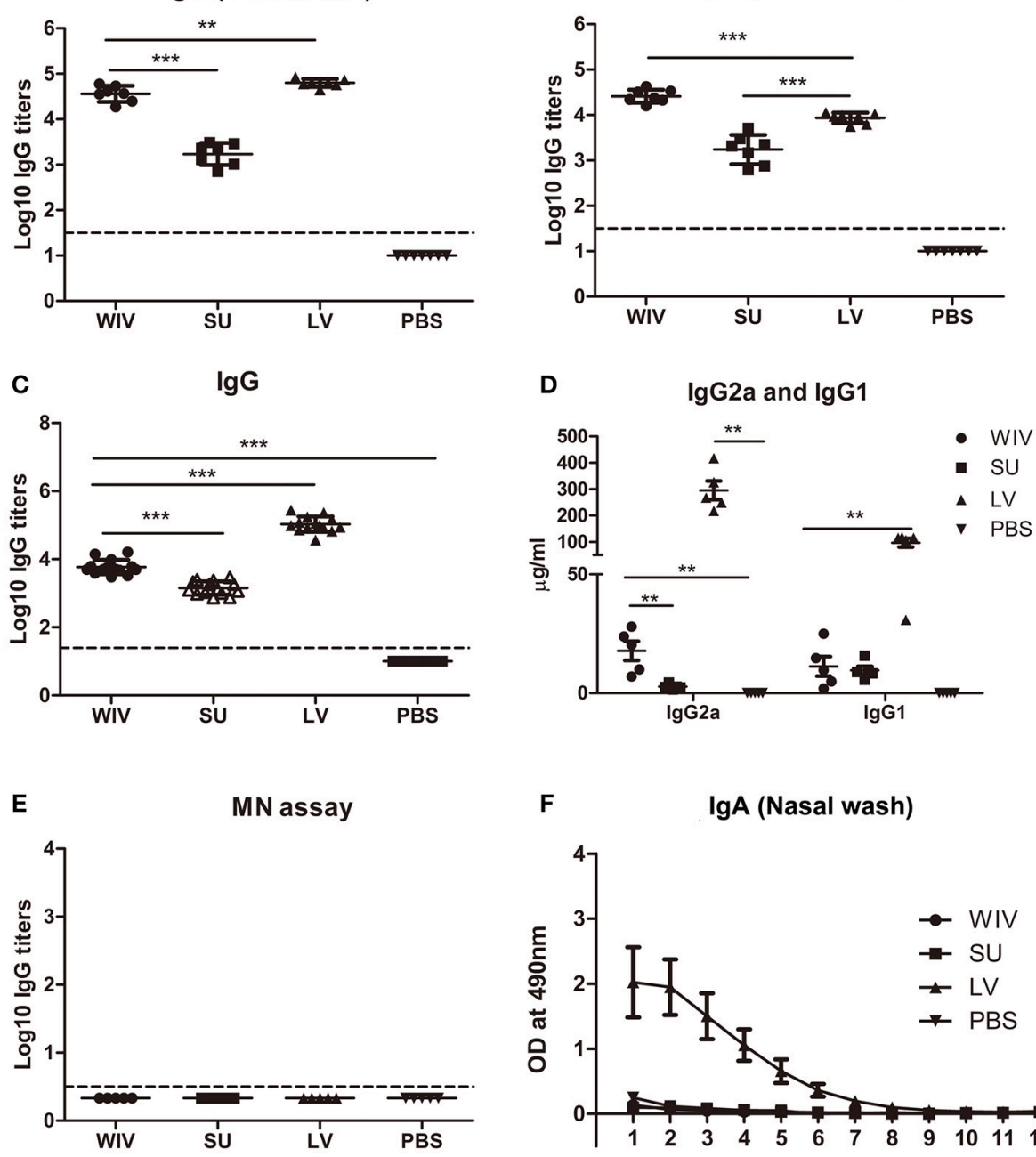

F

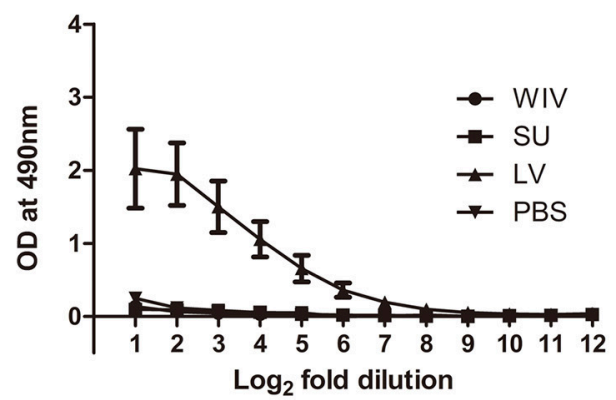

FIGURE 2 | Cross-reactive antibody responses induced by sequential infection or immunization. On day 28 (the day of the second infection or immunization; A) and on day 56 (the day of sacrifice or challenge; B-F), serum samples and nasal washes were collected from the mice described in the legend to Figure 1. Anti-PR8 (HA/NA) IgG antibodies (A; $n=7)$ and Anti-X-31(HA/NA) IgG antibodies (B; $n=7)$ in serum samples were detected by ELISA using PR8 SU and X-31 SU for coating Anti-H1N1pdm09-specific IgG (C; $n=15)$, IgG2a and IgG1 (D; $n=5)$ antibodies in serum samples were detected by ELISA. Microneutralization assay was used to determine the neutralizing ability of these antibodies toward $\mathrm{A}(\mathrm{H} 1 \mathrm{~N} 1)$ pdm09 virus $(\mathbf{E} ; n=5)$. Anti-H1N1pdm09 IgA antibody levels in nasal washes were determined by ELISA (F; $n=5)$. Data of individual animals $(\mathbf{A}-\mathbf{E})$ are depicted or mean values \pm SEM $(\mathbf{F})$ are given, ${ }^{\star \star} p<0.01,{ }^{\star \star \star} p<0.001$. Mann-Whitney $U$-test. The dashed line represents the limit of detection.

also analyzed the presence of cross-reactive antibodies against conserved internal proteins in serum using recombinant NP from HK68 (H3N2), which shows 90\% of sequence homology with NP from $\mathrm{A}(\mathrm{H} 1 \mathrm{~N} 1) \mathrm{pdm} 09$. Sequential infection and WIV vaccination induced similar though somewhat variable amounts of anti-NP antibodies (Figure S1D). As expected, no anti-NP antibody was found in the sequential SU vaccination group.

These data indicate that sequential infection induced broader and higher amounts of cross-reactive non-neutralizing antibodies than sequential WIV vaccination, while SU vaccination induced only antibodies against hemagglutinin and to a limited extent against neuraminidase. Moreover, responses to live virus and WIV were dominated by IgG2a while responses to SU consisted exclusively of IgG1 antibodies.

\section{Sequential Infection, WIV and SU Vaccination Induce Different Memory T Cell Immune Responses}

Apart from cross-reactive antibody response, cellular immune responses also play an important role in cross-protection. We first evaluated the overall memory $\mathrm{T}$ cell responses in spleen and lungs from mice after sequential infections or vaccinations. None of these immunization strategies could significantly enhance 
the number of memory CD4+CD44+ $\mathrm{T}$ cells in the spleen (Figure 3A). In contrast, numbers of CD8+CD44+ T cells were significantly enhanced in the spleens of sequentially infected mice compared with mice of the unvaccinated control group $(p=0.028)$. Also sequential WIV vaccination enhanced the numbers of memory $\mathrm{CD} 8+\mathrm{CD} 44+\mathrm{T}$ cells in the spleen $(p=0.02)$ while SU did not have such an effect. In the lungs, only sequential infection resulted in a moderate but significant increase of memory $\mathrm{T}$ cells and this effect was restricted to CD8+CD44+ T cells (Figure S2A). Interestingly, while the CD8 memory $\mathrm{T}$ cell population in sequentially infected mice consisted of CD62L negative TEM as well as CD62L positive TCM, the majority of memory CD8 $\mathrm{T}$ cells from the sequential WIV vaccination group consisted of TCM (Figure 3B, Figure S2B). These data indicate that sequential infection and sequential immunization with WIV are capable of stimulating CD8 memory responses while immunization with $\mathrm{SU}$ is not.

For detection of $\mathrm{CD} 4+$ and $\mathrm{CD} 8+\mathrm{T}$ cells responding to any influenza protein, splenocytes from sequentially infected or sequentially immunized mice were stimulated overnight with WIV, and IFN $\gamma$ production was assessed by intracellular cytokine staining. In live virus infected mice, percentages of IFN $\gamma$ producing $\mathrm{CD} 4+$ and $\mathrm{CD} 8+$ memory $\mathrm{T}$ cells in spleen and lung were significantly higher than in mock immunized mice (Figure 4A, Figure S2C, $p<0.05$ ). Moreover, around $90 \%$ of the IFN $\gamma$-producing CD8 T cells were effector memory cells (data not shown). Also in WIV immunized mice, enhanced percentages of IFN $\gamma$ positive CD4+ and CD8+ memory T cells were found, yet lower than in the LV group. Significance as compared to PBS control animals was reached only for CD4+ $\mathrm{T}$ cells in spleen.

In order to determine whether infection of vaccination had induced CD8 + T cells to the dominant NP epitope an ELISPOT assay was performed for which the splenocytes were stimulated with $\mathrm{NP}_{366-374}$ peptide (ASNENMDAM) from PR8 virus (the epitope present in PR8 as well as X-31 virus). NP-specific CD8 T cells were detected in the WIV and the sequential infection group, but numbers were around 12 times higher in the latter (Figure 4B, $p=0.008$ ). Next, we assessed the cross-reactivity of these NP-specific CD8 T cells to A(H1N1)pdm09 NP by staining with tetramers containing the ASENENMETM epitope (from $\mathrm{A}(\mathrm{H} 1 \mathrm{~N} 1) \mathrm{pdm} 09$ virus). No tetramer positive CD8 T cells were observed in these groups of mice (Figure 4C) while tetramer positive cells were readily detected in blood of mice infected with $\mathrm{A}(\mathrm{H} 1 \mathrm{~N} 1) \mathrm{pdm} 09$ virus.

\section{Serum Antibodies Induced by Sequential Infection Are Sufficient to Provide Cross-Protection but Antibodies Induced by WIV Vaccination Are Not}

Our data show that sequential infection and sequential immunization with WIV could provide protection against severe symptoms upon infection with an $\mathrm{A}(\mathrm{H} 1 \mathrm{~N} 1) \mathrm{pdm} 09$ virus. To determine the contribution of cross-reactive antibodies against $\mathrm{A}(\mathrm{H} 1 \mathrm{~N} 1) \mathrm{pdm} 09$ virus challenge, serum from sequentially virus infected, WIV vaccinated or PBS control mice was passively transferred to naive mice 1 day before $\mathrm{A}(\mathrm{H} 1 \mathrm{~N} 1) \mathrm{pdm} 09$ virus challenge. Serum from mice vaccinated with WIV derived from $\mathrm{A}(\mathrm{H} 1 \mathrm{~N} 1)$ pdm09 virus served as positive control.

Mice receiving serum from mice immunized with A(H1N1)pdm09 WIV (positive control, neutralizing titer 330) via adoptive transfer did not show weight loss upon $\mathrm{A}(\mathrm{H} 1 \mathrm{~N} 1) \mathrm{pdm} 09$ virus challenge (Figure 5A) and lung virus titers in these animals were decreased by more than 2 logs compared to the titers in the PBS control group (Figure 5B, $p<0.01)$. Similarly, mice receiving serum from the sequential infection group showed no or only mild weight loss. Interestingly, despite the fact that the transferred serum did not contain any neutralizing antibodies, lung virus titers in this group were decreased to the same low level as in mice which had received serum from $\mathrm{A}(\mathrm{H} 1 \mathrm{~N} 1)$ pdm09-immunized mice containing neutralizing antibodies. Also serum from the sequential WIV vaccination group provided partial protection; 4 out of 5 mice receiving this serum showed no or mild weight loss, while one mouse went down quickly. Yet, lung virus titers in the WIV vaccination group, though slightly lower, did not differ significantly from those in PBS-treated controls $(p=0.22)$ (Figure 5B).

These data indicate that non-neutralizing antibodies induced by sequential infection were as effective as neutralizing antibodies induced by $\mathrm{A}(\mathrm{H} 1 \mathrm{~N} 1) \mathrm{pdm} 09$ WIV vaccination in providing protection against $\mathrm{A}(\mathrm{H} 1 \mathrm{~N} 1) \mathrm{pdm} 09$ virus challenge. However, non-neutralizing antibody induced by sequential WIV vaccination were not sufficient to provide full cross-protection.

\section{Memory T Cells Induced by Sequential Live Virus Infection or WIV Vaccination Are Involved in Cross-Protection Against A(H1N1)pdm09 Virus Challenge}

To determine the contribution of $\mathrm{T}$ cell immune responses to cross-protection against $\mathrm{A}(\mathrm{H} 1 \mathrm{~N} 1)$ pdm09 virus infection, we used CD4 or CD8 specific antibodies to deplete $\mathrm{T}$ cells before and during $\mathrm{A}(\mathrm{H} 1 \mathrm{~N} 1)$ pdm09 challenge. On day 6 post-challenge, we confirmed that $95 \%$ of CD8 T cells or $96 \%$ of CD 4 T cells in mice spleen were depleted by this treatment (data not shown).

Mice in the PBS mock vaccination group, no matter whether treated with PBS, CD4 depletion antibody or CD8 depletion antibody, showed continuous weight loss after A(H1N1)pdm09 challenge (Figure 6A, PBS) and displayed the same virus titers in lung tissue on day 6 post-infection (Figure 6B, PBS). In contrast, mice in the sequential infection group were protected from weight loss and showed low or undetectable lung virus titers (Figure 6A, LV). Depletion of CD4 T cells in these mice had no effect on protection. Depletion of CD8 T cells in the sequential infection group had some effect on protection from weight loss; on day 6 post $\mathrm{A}(\mathrm{H} 1 \mathrm{~N} 1)$ pdm09 virus challenge 3 out of 6 mice had lost $>6.5 \%$ weight while in non-depleted mice the most severe weight loss was $2.1 \%$ and was observed in a single mouse only (Figure 6A, LV). In addition, lung virus titers were about $1.5 \log _{10}$ higher in the CD8-depleted mice than in non-depleted control mice of the sequential infection group; yet, virus titers were still significantly lower than in non-immunized mice. In the 


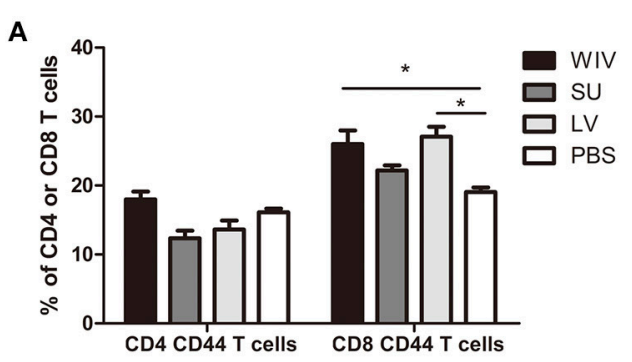

B

Spleen
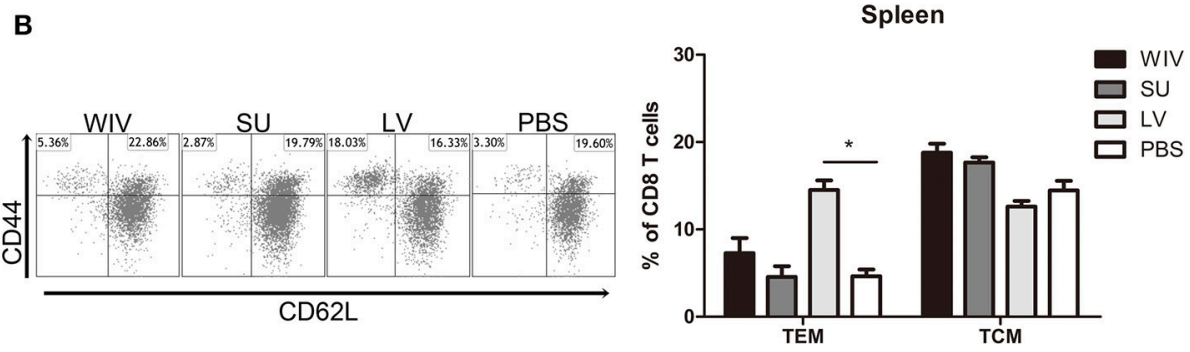

FIGURE 3 | Memory T cell immune responses after sequential infection or immunization. Of the mice described in the legend to Figure 1,5 animals/group were sacrificed 28 days after the second infection or immunization and spleen and lung were collected. (A) CD4 ${ }^{+} \mathrm{CD} 44^{+}$and $\mathrm{CD} 8^{+} \mathrm{CD} 44^{+}$memory T cells in spleen were determined by flow cytometry. (B) CD8 ${ }^{+} \mathrm{CD} 44^{+}{ }^{C D} 62 \mathrm{~L}^{-}$effector memory $\mathrm{T}$ cells (TEM) and $\mathrm{CD} 8^{+} \mathrm{CD} 44^{+} \mathrm{CD} 62 \mathrm{~L}^{+}$central memory T cells (TCM) in spleen. Left: representative dot plots depicting CD44 and CD62L expression on spleen CD8T cells. Right: percentages of spleen CD8 TEM and TCM + SEM. $(n=4$ or 5 per group, representative of two experiments, Mann-Whitney $U$-test, $\left.{ }^{*} p<0.05\right)$.

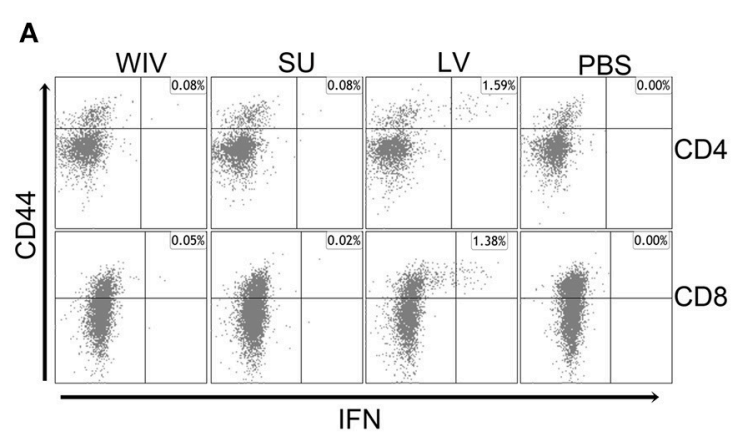

B

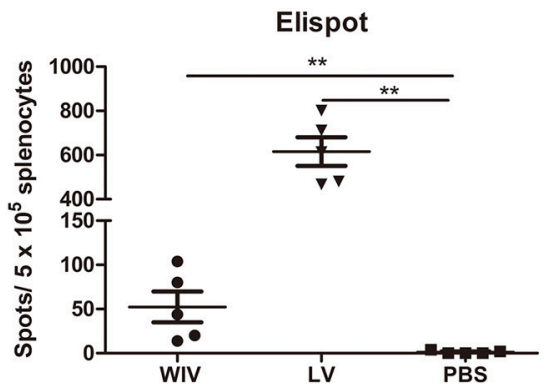

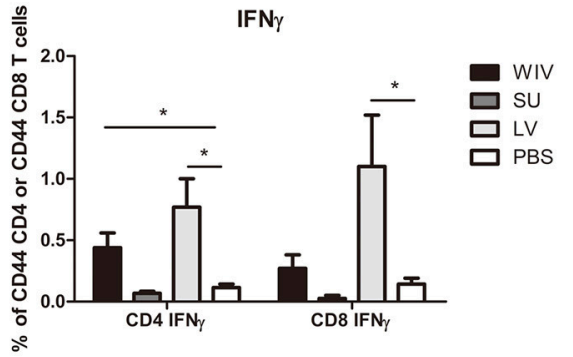

C

Tetramer assay

(pdmH1N1 NP $366-374-$ Specific T cells)

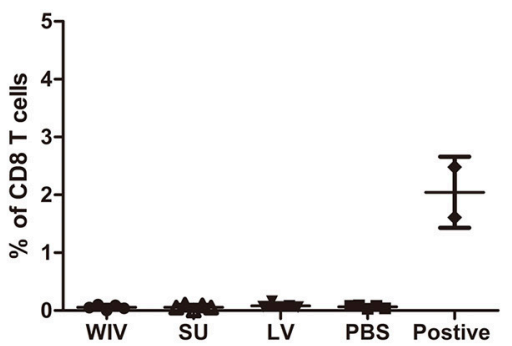

FIGURE 4 | Influenza-specific T cell immune responses induced by sequential infection or immunization. (A) Splenocytes harvested on day 28 post the second infection/vaccination, were stimulated with $\mathrm{A}(\mathrm{H} 1 \mathrm{N1}) \mathrm{pdm} 09$ WIV and anti-CD28 overnight in presence of protein transport inhibitor. Presence of intracellular IFN $\gamma$ in $\mathrm{CD}^{+}{ }^{\mathrm{CD}} 44^{+}$and $\mathrm{CD} 8{ }^{+} \mathrm{CD} 44^{+} \mathrm{T}$ cells was analyzed by flow cytometry. Left: representative dot plots of stimulated CD4 or CD8 T cells stained for CD44 and IFN $\gamma$. Right: percentages of IFN $\gamma$-producing cells among $\mathrm{CD} 4^{+} \mathrm{CD} 44^{+}$and $\mathrm{CD}^{+}{ }^{+} \mathrm{CD} 44^{+} \mathrm{T}$ cells. $(n=4$ or 5 , representative of two experiments, Mann-Whitney $\mathrm{U}$-test, $\left.{ }^{*} p<0.05\right)$. (B) On day 28 post the second infection/immunization, $\mathrm{NP}_{366-374}$ of PR8 virus was used to stimulate mouse splenocytes and IFN $\gamma$-producing $C D 8 T$ cells were enumerated by ELISPOT. ( $n=5$, Mann-Whitney $U$ test, $\left.{ }^{* *} p<0.01\right)$. (C) A(H1N1)pdm09 NP $366-374$-specific CD8T cells in spleens of infected/immunized mice $(n=5)$ were determined by tetramer assay. Lymphocytes from the blood of mice $(n=2)$ infected with $\mathrm{A}(\mathrm{H} 1 \mathrm{~N} 1)$ pdm09 virus served as positive control. 
A
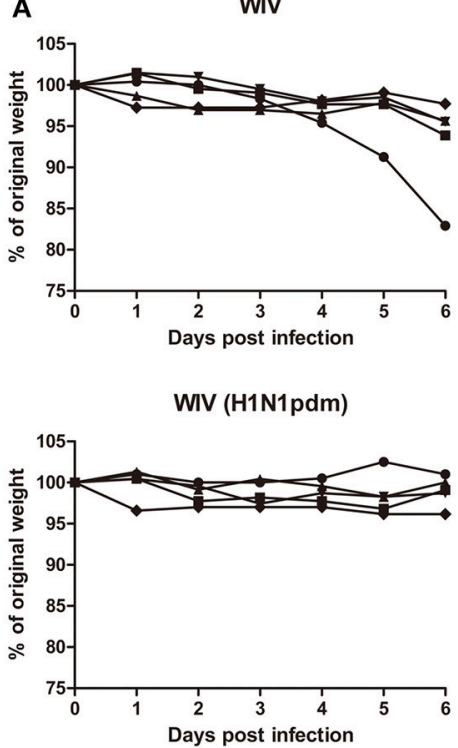

LV

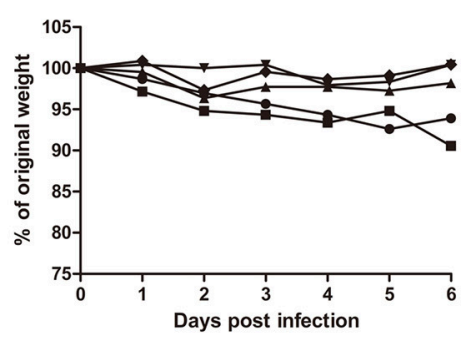

B

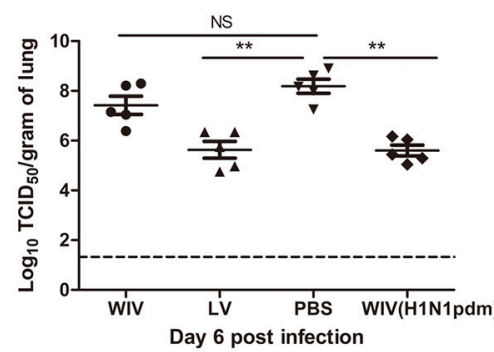

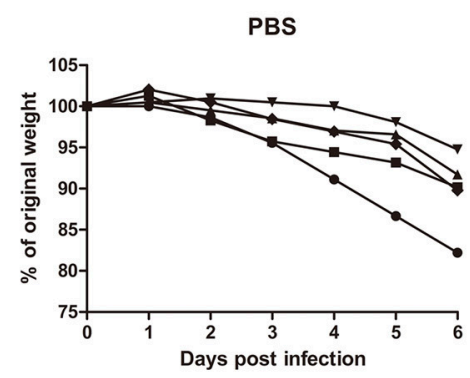

FIGURE 5 | The cross-protective potential of antibodies induced by sequential infection or immunization. Mice $(n=5)$ were primed with PR8 virus $\left(10^{3} T C I D_{50}\right)$ or PR8 WIV $(15 \mu \mathrm{g})$ and boosted with X-31 virus $\left(10^{3} \mathrm{TCID}_{50}\right)$ or X-31 WIV $(15 \mu \mathrm{g})$. Mice primed and boosted with PBS served as negative control and mice primed and boosted with $\mathrm{A}(\mathrm{H} 1 \mathrm{~N} 1)$ pdm09 WIV $(15 \mu \mathrm{g})$ served as positive control. Sera from these mice were collected 4 weeks after boost, pooled and injected into naiive mice 1 day before challenge with A/California/7/2009 (H1N1)pdm09 virus. Body weight loss (A) was monitored daily for 6 days. Virus titers in the lung tissue (B) on day 6 post-challenge were determined by titration on MDCK cells. ${ }^{* *} p<0.01$, Mann-Whitney $U$-test. The dashed line represents limit of detection. NS, not significant.

WIV vaccination group, depletion of CD4 or CD8 T cell did not significantly alter the weight loss compared with mock depletion but a strong trend toward less weight loss was observed in mice depleted for CD4 T cells as compared to non-depleted mice of this group $(P=0.054$, Figure 6A, WIV). Depletion of CD4 T cells decreased and depletion of CD8 T cells increased lung virus titers by about $1 \log$ as compared to non-depleted animals on day 6 post challenge but these trends did not reach statistical significance (Figure 6B, WIV). Moreover, virus titers in WIV-immunized CD8 $\mathrm{T}$ cell-depleted mice were of the same magnitude as those in the PBS mock vaccination group.

These data above suggests that CD4 memory $\mathrm{T}$ cells were most likely not involved in cross-protection while CD8 memory $\mathrm{T}$ cells induced by sequential infection or WIV immunization contributed decisively to cross-protection.

\section{DISCUSSION}

To determine whether sequential immunization with antigenically distinct traditional vaccines could provide cross-protection, mice were sequentially immunized with WIV or SU vaccines derived from PR8 and X-31 viruses and then challenged with an $\mathrm{A}(\mathrm{H} 1 \mathrm{~N} 1) \mathrm{pdm} 09$ virus. Another group of mice was sequentially infected with sublethal doses of PR8 followed by $\mathrm{X}-31$ prior to $\mathrm{A}(\mathrm{H} 1 \mathrm{~N} 1) \mathrm{pdm} 09$ virus challenge. We demonstrate that sequential infection provided solid crossprotection which was correlated with cross-protective antibodies and CD8 TEM cells. Sequential vaccination with WIV provided partial cross-protection which also correlated with induction of cross-reactive antibodies and CD8 T cells. Yet, sequential SU vaccination did not provide cross-protection.

Neither sequential infection nor sequential immunization resulted in induction of antibodies capable of neutralizing $\mathrm{A}(\mathrm{H} 1 \mathrm{~N} 1) \mathrm{pdm} 09$ virus. Yet, substantial amounts of cross-reactive non-neutralizing antibodies were induced. Previous publications have shown that non-neutralizing antibodies, for example antiHA stem antibodies, can be induced by sequential infection with antigenically distinct viruses and may provide crossprotection against $\mathrm{A}(\mathrm{H} 1 \mathrm{~N} 1) \mathrm{pdm} 09$ influenza virus infection $(11,12)$. In contrast to these findings, no anti-HA stem antibodies were found in this study. This may be due to the fact that the two virus strains (PR8 and X-31) used for infection/immunization belong to two different phylogenetic groups. The HA-stem regions from PR8 and X-31 virus show low similarity, which might have impaired boosting of HAstem reactive $\mathrm{B}$ cells induced by $\mathrm{PR} 8$ through exposure to $\mathrm{X}-31$. Nevertheless, we found cross-reactive antibodies against other conserved proteins in this study. Anti-M2e, anti-NP and anti-NA antibodies were induced by sequential infection and, although to a lesser extent, by sequential WIV immunization. In contrast, sequential SU immunization induced only very moderate amounts of anti-NA antibodies cross-reactive with $\mathrm{A}(\mathrm{H} 1 \mathrm{~N} 1) \mathrm{pdm} 09$ virus.

Since no neutralizing antibodies were found, the crossreactive but non-neutralizing antibodies likely are the reason for the cross-protection observed in the serum adoptive transfer experiment. Non-neutralizing antibodies can provide 
A

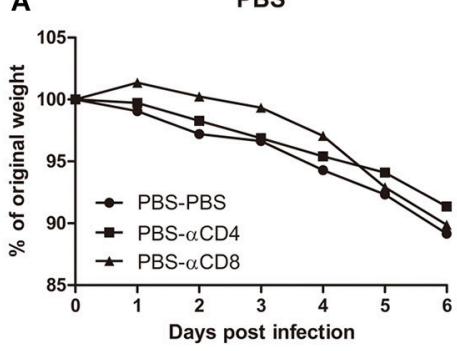

B

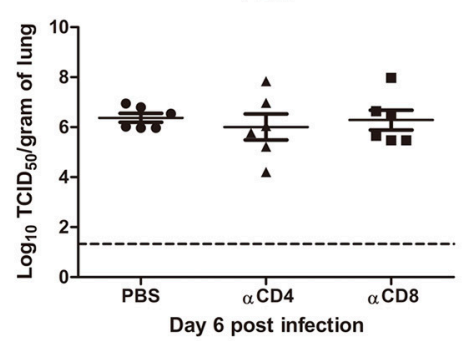

LV

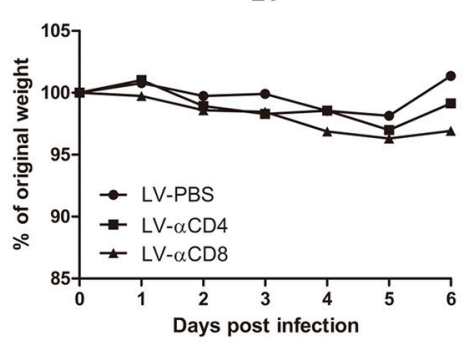

LV

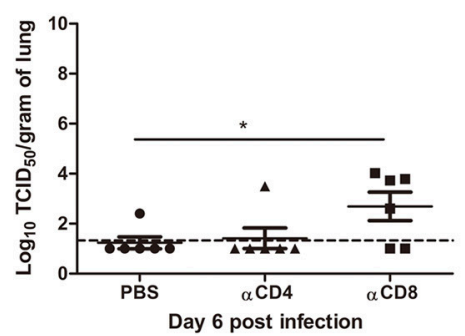

WIV

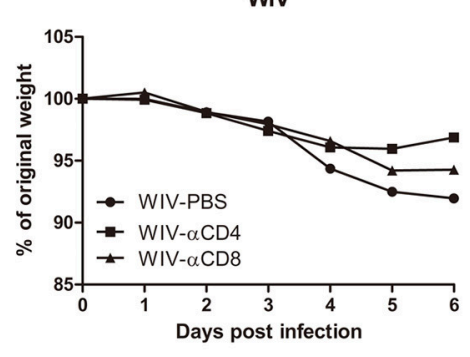

WIV

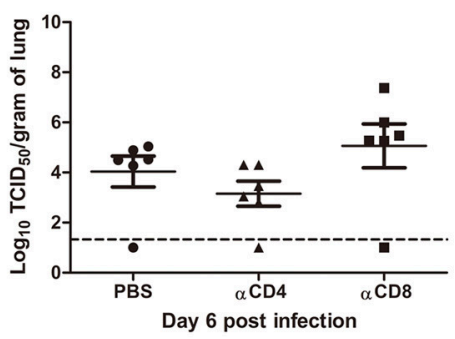

FIGURE 6 | The cross-protective potential of CD4 T cells and CD8 T cells induced by sequential infection or immunization. Mice were primed with PR8 virus $\left(10^{3} \mathrm{TCID}_{50}\right)$ or PR8 WIV $(15 \mu \mathrm{g})$ and then boosted with X-31 virus (10 $\left.{ }^{3} \mathrm{TCID} 5\right)$ or X-31 WIV (15 $\left.\mu \mathrm{g}\right)$. Mice primed and boosted with PBS served as control. Anti-CD4 or anti-CD8 T cell depletion antibody or PBS were injected intraperitoneally into mice on day $-1,1$, and 3 of $A(H 1 N 1)$ pdm09challenge. Weight loss (A) was monitored for 6 days and lung virus titers (B) were determined on day 6 post-infection by titration on MDCK cells. ${ }^{*} p<0.05$, Mann-Whitney $U$ test. The dashed line represents limit of detection.

cross-protection via $\mathrm{Fc}$ receptor dependent mechanisms [reviewed in (44)]. Interestingly, control of lung virus growth by non-neutralizing antibodies evoked by sequential infection with PR8 and X-31 was as effective as by neutralizing antibodies evoked by $\mathrm{A}(\mathrm{H} 1 \mathrm{~N} 1)$ pdm09 WIV. Even in absence of antigenspecific $\mathrm{T}$ cells, neutralizing antibodies are thus not crucial for protection, suggesting that non-neutralizing antibodies maybe more important for cross-protection than generally thought. Our results are in line with studies in macaques which also demonstrate that non-neutralizing but cross-reactive antibodies can provide effective protection against heterosubtypic virus challenge, most likely through antibody dependent cellular cytotoxicity $(45,46)$. In this context, it is interesting that recent studies revealed that in humans antibodies cross-reacting with different influenza virus strains are common and are effectively enhanced by vaccination with seasonal influenza vaccines $(47,48)$. These antibodies might play a role in disease mitigation.

Hillaire et al. and Guo et al. have shown that one dose of serum from virus-infected animals could not provide cross-protection against $\mathrm{A}(\mathrm{H} 1 \mathrm{~N} 1) \mathrm{pdm} 09$ virus infection in mice $(5,6)$, while Fang et al. have shown that four doses of serum could provide cross-protection(3). These studies imply that the amount of nonneutralizing cross-reactive antibodies may also play an important role in cross-protection. In the present study, cross-reactive antibody titers evoked by sequential WIV immunization were 20fold lower than those evoked by sequential infection. We thus speculate that antibodies induced by WIV immunization, though in principle cross-protective as indicated by our data, were not present in sufficient amounts to confer complete protection.
Although sequential infection and sequential WIV immunization induced virus-specific IFN $\gamma$-producing CD4 T cells, depletion of CD4 T cells in this study did not influence the cross-protection, neither in the sequential infection group nor in the sequential WIV vaccination group. These results contrast with previous findings which indicate that CD4 T cells might play a role in cross-protection $(5,6,21)$. Hillaire et al. reported that naïve mice that received $\mathrm{T}$ cells (a mixture of CD4 and CD8 T cells) induced by a single $\mathrm{A}(\mathrm{H} 3 \mathrm{~N} 2)$ (HK68) virus infection acquired better cross-protection against $\mathrm{A}(\mathrm{H} 1 \mathrm{~N} 1)$ pdm09 virus infection than naïve mice that received purified CD8 T cells only (6). Another study by Guo et al. reported that depletion of CD4 $\mathrm{T}$ cells induced by a single $\mathrm{X}-31$ virus infection impaired the cross-protection against $\mathrm{A}(\mathrm{H} 1 \mathrm{~N} 1) \mathrm{pdm} 09$ virus infection in mice (5). In this study, not only CD4 $\mathrm{T}$ cells, but also robust cross-reactive antibodies and CD8 T cell immune responses were induced by sequential infection. These antibodies or CD8 T cells alone could significantly reduce the virus titer in mice lung in the absence of CD4 T cells. We conclude that CD4 T cell are not essential for cross-protection against A(H1N1)pdm09 during infection in this mouse model.

CD8 $\mathrm{T}$ cells play an important role in cross-protection. In the present study, depletion of CD8 T cells induced by sequential WIV immunization resulted in lung virus titers similar to those in PBS mock vaccinated mice, implying that CD8 T cells are important for cross-protection induced by sequential WIV immunization. These results agree with those reported by Furuya et al. who showed that WIV (prepared by $\gamma$-irradiation) did not provide cross-protection against heterologous virus infection in mice defective in CD8 T cells (49). Another study by Budimir 
et al. also has shown that depletion of CD8 $\mathrm{T}$ cells induced by 2 doses of WIV abolished the cross-protection against heterologous virus challenge (50). Depletion of CD8 T cells in the sequential infection group prior to $\mathrm{A}(\mathrm{H} 1 \mathrm{~N} 1) \mathrm{pdm} 09$ challenge had a significant though moderate effect on lung virus titers. This result implies that in the sequential infection group CD8 $\mathrm{T}$ cells do play a role in cross-protection, but team up with other mechanisms, eg antibodies (Figure 5), to provide full protection. Our findings are also in line with previous publications which demonstrate that CD4 $\mathrm{T}$ cells or antibody immune responses are required to cooperate with CD8 $\mathrm{T}$ cells for providing optimal cross-protection in live virus infected mice $(5,17,51)$.

The tetramer experiment indicates that PR8 NP $366-374$ epitope-specific CD8 T cells elicited by PR8 and boosted by $\mathrm{X}-31$ virus or WIV could not recognize the corresponding $\mathrm{A}(\mathrm{H} 1 \mathrm{~N} 1)$ pdm09 $\mathrm{NP}_{366-374}$ epitope. This result is in line with previous findings demonstrating that $\mathrm{X}-31 \mathrm{NP}_{366-374}$ epitope cannot be recognized by $\mathrm{A}(\mathrm{H} 1 \mathrm{~N} 1) \mathrm{pdm} 09 \mathrm{NP}$-specific CD8 T cells (52). However, Guo et al. have reported that influenza NP and $\mathrm{PA}$ proteins from $\mathrm{PR} 8$ and $\mathrm{A}(\mathrm{H} 1 \mathrm{~N} 1) \mathrm{pdm} 09$ virus share many conserved epitopes (52). It is possible that influenza-specific CD8 T cells against these shared conserved epitopes induced by sequential infection or WIV immunization contributed to cross-protection against $\mathrm{A}(\mathrm{H} 1 \mathrm{~N} 1) \mathrm{pdm} 09$ influenza virus infection.

Different phenotypes of memory CD8 T cells show different capacities in cross-protection, for example $\mathrm{Wu}$ et al. have shown that CD8 TCM induced by influenza virus infection are not required for cross-protection (17). In the present study, we found that sequential infection mainly induced CD8 TEM. This result is in line with previous findings in mice and humans reporting that a single influenza infection predominantly induces influenzaspecific CD8 TEM cells $(53,54)$. CD8 TEM have been shown to be associated with a fast recall immune response to the infection site, thus providing immediate cross-protection(53). Interestingly, we found that sequential WIV immunization was more likely to induce CD8 TCM. These cells have shown high proliferation ability in secondary lymphoid organs but to provide delayed cross-protection (55). Thus, we propose that CD8 TEM in lung and spleen induced by sequential infection provided immediate local antiviral effects, resulting in solid cross-protection. In contrast, CD8 TCM in spleen induced by sequential WIV immunization provided delayed antiviral effects in the lung, resulting in partial cross-protection.

A limitation of our study is the fact that we did not investigate whether sequential infection/immunization with the same virus could also provide protection from infection by a heterologous

\section{REFERENCES}

1. Wiersma L, Rimmelzwaan G, de Vries R. Developing universal influenza vaccines: hitting the nail, not just on the head. Vaccines (2015) 3:239-62. doi: 10.3390/vaccines3020239

2. Krammer F, Palese P. Advances in the development of influenza virus vaccines. Nat Rev Drug Discov. (2015) 14:167-82. doi: 10.1038/nrd4529 virus subtype. We therefore cannot formally conclude that antigenically distinct viruses are required to induce crossprotection. However, it has been well established that vaccination with distinct vaccines focuses the immune response on conserved antigens which would be a clear benefit when attempting to raise cross-protection.

In summary, sequential infection with antigenically distinct viruses provided robust cross-protection against $\mathrm{A}(\mathrm{H} 1 \mathrm{~N} 1) \mathrm{pdm} 09$ virus infection. Yet, sequential immunization with antigenically distinct SU failed to provide cross-protection. Intriguingly, sequential immunization with antigenically distinct WIV provided partial cross-protection by a mechanism involving cross-reactive but non-neutralizing antibodies as well as CD8+ $\mathrm{T}$ cells. These results imply that sequential immunization with WIV prepared from antigenically distinct viruses could be used to alleviate the severity of virus infection if a new pandemic occurs.

\section{AUTHOR CONTRIBUTIONS}

WD, YB, FS, TM, and JdV-I performed animal experiments. KG, $\mathrm{OE}, \mathrm{LB}, \mathrm{CdH}, \mathrm{GC}$, and NT contributed materials and reagents. WD, CdH, GC, NT, and AH analyzed the data. WD and AH wrote the manuscript. WD, DK, and AH designed the study. All authors approved the manuscript.

\section{ACKNOWLEDGMENTS}

The authors would like to thank Meiling Dai, Utrecht University, Utrecht, The Netherlands, for technical assistance and David A. Price, Institute of Infection and Immunity, Cardiff University School of Medicine, Cardiff, United Kingdom, for a gift of tetramers. This research was funded by the European Union Seventh Framework Program 19 (FP7/2007-2013) Universal Influenza Vaccines Secured (UNISEC) consortium under grant agreement no. 602012 and by the EU Horizon 2020 Program under the Marie Skłodowska-Curie grant agreement 713660. DW received a $\mathrm{PhD}$ scholarship from the University Medical Center Groningen, Groningen, The Netherlands, and Shantou University Medical College, Shantou, China. This manuscript has been released as a preprint at https://www.biorxiv.org/content/ early/2018/05/31/335281.

\section{SUPPLEMENTARY MATERIAL}

The Supplementary Material for this article can be found online at: https://www.frontiersin.org/articles/10.3389/fimmu. 2018.02312/full\#supplementary-material 
challenge with 2009 pandemic H1N1 Virus. J Virol. (2012) 86:8625-33. doi: 10.1128/JVI.00147-12

5. Guo H, Santiago F, Lambert K, Takimoto T, Topham DJ. T cell-mediated protection against lethal 2009 pandemic H1N1 influenza virus infection in a mouse model. J Virol. (2011) 85:448-55. doi: 10.1128/JVI.01812-10

6. Hillaire MLB, van Trierum SE, Kreijtz JHCM, Bodewes R, Geelhoed-Mieras MM, Nieuwkoop NJ, et al. Cross-protective immunity against influenza pH1N1 2009 viruses induced by seasonal influenza A (H3N2) virus is mediated by virus-specific T-cells. J General Virol. (2011) 92:2339-49. doi: 10.1099/vir.0.033076-0

7. Carter DM, Bloom CE, Nascimento EJM, Marques ETA, Craigo JK, Cherry JL, et al. Sequential seasonal H1N1 influenza virus infections protect ferrets against novel 2009 H1N1 influenza virus. J Virol. (2013) 87:1400-10. doi: 10.1128/JVI.02257-12

8. Laurie KL, Carolan LA, Middleton D, Lowther S, Kelso A, Barr IG. Multiple infections with seasonal influenza $\mathrm{A}$ virus induce cross-protective immunity against $\mathrm{A}(\mathrm{H} 1 \mathrm{~N} 1)$ pandemic influenza virus in a ferret model. J Infect Dis. (2010) 202:1011-20. doi: 10.1086/656188

9. Sridhar S, Begom S, Bermingham A, Hoschler K, Adamson W, Carman W, et al. Cellular immune correlates of protection against symptomatic pandemic influenza. Nat Med. (2013) 19:1305-12. doi: 10.1038/nm.3350

10. Hayward AC, Wang L, Goonetilleke N, Fragaszy EB, Bermingham A, Copas A, et al. Natural T cell-mediated protection against seasonal and pandemic influenza: results of the flu watch cohort study. Am J Resp Crit Care Med. (2015) 191:1422-31. doi: 10.1164/rccm.201411-1988OC

11. Kirchenbaum GA, Carter DM, Ross TM. Sequential Infection in Ferrets with Antigenically Distinct Seasonal H1N1 Influenza Boosts Hemagglutinin StalkSpecific Antibodies. J Virol. (2015) 90:1116-28. doi: 10.1128/JVI.02372-15

12. Margine I, Hai R, Albrecht RA, Obermoser G, Harrod AC, Banchereau J, et al. H3N2 Influenza virus infection induces broadly reactive hemagglutinin stalk antibodies in humans and mice. J Virol. (2013) 87:4728-37. doi: 10.1128/JVI.03509-12

13. Couch RB, Atmar RL, Franco LM, Quarles JM, Wells J, Arden N, et al. Antibody correlates and predictors of immunity to naturally occurring influenza in humans and the importance of antibody to the neuraminidase. J Infect Dis. (2013) 207:974-81. doi: 10.1093/infdis/jis935

14. DiLillo DJ, Tan GS, Palese P, Ravetch J V. Broadly neutralizing hemagglutinin stalk-specific antibodies require $\mathrm{F} c \gamma \mathrm{R}$ interactions for protection against influenza virus in vivo. Nat Med. (2014) 20:143-51. doi: 10.1038/nm.3443

15. El Bakkouri K, Descamps F, De Filette M, Smet A, Festjens E, Birkett A, et al. Universal vaccine based on ectodomain of matrix protein 2 of influenza A: Fc receptors and alveolar macrophages mediate protection. J Immunol. (2011) 186:1022-31. doi: 10.4049/jimmunol.0902147

16. LaMere MW, Lam H-T, Moquin A, Haynes L, Lund FE, Randall $\mathrm{TD}$, et al. Contributions of antinucleoprotein IgG to heterosubtypic immunity against influenza virus. J Immunol. (2011) 186:4331-9. doi: 10.4049/jimmunol.1003057

17. Wu T, Hu Y, Lee Y-T, Bouchard KR, Benechet A, Khanna K, et al. Lung-resident memory CD8 T cells (TRM) are indispensable for optimal cross-protection against pulmonary virus infection. J Leukocyte Biol. (2014) 95:215-24. doi: 10.1189/jlb.0313180

18. Kreijtz JHCM, Bodewes R, van den Brand JM, de Mutsert G, Baas C, van Amerongen $\mathrm{G}$, et al. Infection of mice with a human influenza A/H3N2 virus induces protective immunity against lethal infection with influenza $\mathrm{A} / \mathrm{H} 5 \mathrm{~N} 1$ virus. Vaccine (2009) 27:4983-9. doi: 10.1016/j.vaccine.2009.05.079

19. Alam S, Sant AJ. Infection with seasonal influenza virus elicits CD4 T cells specific for genetically conserved epitopes that can be rapidly mobilized for protective immunity to pandemic H1N1 influenza virus. J Virol. (2011) 85:13310-21. doi: 10.1128/JVI.05728-11

20. Eliasson DG, Omokanye A, Schön K, Wenzel UA, Bernasconi V, Bemark M, et al. M2e-tetramer-specific memory CD4 T cells are broadly protective against nfluenza infection. Mucosal Immunol. (2018) 11:273-89. doi: $10.1038 / \mathrm{mi} .2017 .14$

21. Swain SL, McKinstry KK, Strutt TM. Expanding roles for $\mathrm{CD}^{+} \mathrm{T}$ cells in immunity to viruses. Nat Rev Immunol. (2012) 12:136-48. doi: $10.1038 /$ nri3152

22. Wang Z, Wan Y, Qiu C, Quiñones-Parra S, Zhu Z, Loh L, et al. Recovery from severe H7N9 disease is associated with diverse response mechanisms dominated by CD8 ${ }^{+} \mathrm{T}$ cells. Nat Commun. (2015) 6:6833. doi: $10.1038 /$ ncomms 7833

23. Wilkinson TM, Li CKF, Chui CSC, Huang AKY, Perkins M, Liebner JC, et al. Preexisting influenza-specific $\mathrm{CD} 4^{+} \mathrm{T}$ cells correlate with disease protection against influenza challenge in humans. Nat Med. (2012) 18:274-80. doi: $10.1038 / \mathrm{nm} .2612$

24. Jefferies S, Earl D, Berry N, Blackmore T, Rooker S, Raymond N, et al. Effectiveness of the 2009 seasonal influenza vaccine against pandemic influenza $\mathrm{A}(\mathrm{H} 1 \mathrm{~N} 1) 2009$ in healthcare workers in New Zealand, June-August 2009. Euro Surveill (2011) 16:19761. doi: 10.2807/ese.16.02. 19761-en

25. Hardelid P, Fleming DM, Mcmenamin J, Andrews N, Robertson C, SebastianPillai P, et al. Effectiveness of pandemic and seasonal influenza vaccine in preventing pandemic influenza $\mathrm{A}(\mathrm{H} 1 \mathrm{~N} 1) 2009$ infection in England and Scotland 2009-2010. Eurosurveillance (2011) 16:1-7. doi: 10.2807/ese.16.02.19763-en

26. Hancock K, Veguilla V, Lu X, Zhong W, Butler EN, Sun H, et al. CrossReactive Antibody Responses to the 2009 Pandemic H1N1 Influenza Virus. N Engl J Med. (2009) 361:1945-52. doi: 10.1056/NEJMoa0906453

27. Skowronski DM, de Serres G, Crowcroft NS, Janjua NZ, Boulianne N, Hottes TS, et al. Association between the 2008-09 seasonal influenza vaccine and pandemic H1N1 illness during spring-summer 2009: Four observational studies from Canada. PLoS Med. (2010) 7:e1000258. doi: 10.1371/journal.pmed.1000258

28. Janjua NZ, Skowronski DM, Hottes TS, Osei W, Adams E, Petric M, et al. Seasonal influenza vaccine and increased risk of pandemic A/H1N1-related illness: first detection of the association in British Columbia, Canada. Clin Infect Dis. (2010) 51:1017-27. doi: 10.1086/656586

29. Chen GL, Min J-Y, Lamirande EW, Santos C, Jin H, Kemble G, et al. Comparison of a live attenuated $2009 \mathrm{H} 1 \mathrm{~N} 1$ vaccine with seasonal influenza vaccines against 2009 pandemic H1N1 virus infection in mice and ferrets. $J$ Infect Dis. (2011) 203:930-6. doi: 10.1093/infdis/jiq144

30. Ellebedy AH, Ducatez MF, Duan S, Stigger-Rosser E, Rubrum AM, Govorkova $\mathrm{EA}$, et al. Impact of prior seasonal influenza vaccination and infection on pandemic A (H1N1) influenza virus replication in ferrets. Vaccine (2011) 29:3335-39. doi: 10.1016/j.vaccine.2010.08.067

31. Pascua PNQ, Song M-S, Lee JH, Park KJ, Kwon H-I, Baek YH, et al. Evaluation of the efficacy and cross-protectivity of recent human and swine vaccines against the pandemic (H1N1) 2009 virus infection. PLoS ONE (2009) 4:e8431. doi: 10.1371 /journal.pone. 0008431

32. Kim JH, Reber AJ, Kumar A, Ramos P, Sica G, Music N, et al. Non-neutralizing antibodies induced by seasonal influenza vaccine prevent, not exacerbate A(H1N1)pdm09 disease. Sci Rep. (2016) 6:1-13. doi: 10.1038/srep37341

33. Krammer F, Pica N, Hai R, Tan GS, Palese P. Hemagglutinin stalkreactive antibodies are boosted following sequential infection with seasonal and pandemic H1N1 influenza virus in mice. J Virol. (2012) 86:10302-7. doi: 10.1128/JVI.01336-12

34. Krammer F. Strategies to induce broadly protective antibody responses to viral glycoproteins. Exp Rev Vaccines (2017) 16:503-13. doi: 10.1080/14760584.2017.1299576

35. Krammer F, Pica N, Hai R, Margine I, Palese P. Chimeric hemagglutinin influenza virus vaccine constructs elicit broadly protective stalk-specific antibodies. J Virol. (2013) 87:6542-50. doi: 10.1128/JVI.00641-13

36. Wei C-J, Boyington JC, McTamney PM, Kong W-P, Pearce MB, Xu L, et al. Induction of broadly neutralizing $\mathrm{H} 1 \mathrm{~N} 1$ influenza antibodies by vaccination. Science (2010) 329:1060-4. doi: 10.1126/science.1192517

37. Ryder AB, Nachbagauer R, Buonocore L, Palese P, Krammer F, Rose JK. Vaccination with vesicular stomatitis virus-vectored chimeric hemagglutinins protects mice against divergent influenza virus challenge strains. J Virol. (2016) 90:2544-50. doi: 10.1128/JVI.02598-15

38. Zhou H, Huang Y, Yuan S, Li Y, Wu S, Xu J, et al. Sequential immunization with consensus influenza hemagglutinins raises cross-reactive neutralizing antibodies against various heterologous HA strains. Vaccine. (2017) 35:305-12. doi: 10.1016/j.vaccine.2016.11.051

39. Liu H, Patil HP, de Vries-Idema J, Wilschut J, Huckriede A. Enhancement of the immunogenicity and protective efficacy of a mucosal influenza subunit vaccine by the saponin adjuvant GPI-0100. PLoS ONE (2012) 7:e52135. doi: 10.1371/journal.pone.0052135 
40. Reed LJ, Muench H A simple method of estimating fifty percent endpoints. Am J Hyg. (1938) 27:493-497.

41. Dai M, Guo H, Dortmans JCFM, Dekkers J, Nordholm J, Daniels R. Identification of residues that affect oligomerization and / or enzymatic activity of influenza virus H5N1 Neuraminidase Proteins. J Virol. (2016) 90:9457-70. doi: 10.1128/JVI.01346-16

42. Temperton NJ, Hoschler K, Major D, Nicolson C, Manvell R, Hien M. A sensitive retroviral pseudotype assay for influenza H5N1neutralizing antibodies. Influenza Other Respir Viruses (2007) 1:105-12. doi: $10.1111 / \mathrm{j} .1750-2659.2007 .00016 . \mathrm{x}$

43. Ferrara F, Temperton N. MethodsX Chimeric in $\mathrm{fl}$ uenza haemagglutinins : generation and use in pseudotype neutralization assays. MethodsX (2017) 4:11-24. doi: 10.1016/j.mex.2016.12.001

44. Jegaskanda S, Vanderven HA, Wheatley AK, Stephen J. Fc or not Fc; that is the question : antibody Fc-receptor interactions are key to universal influenza vaccine design. Hum Vaccin Immunother. (2017) 13:1-9. doi: 10.1080/21645515.2017.1290018

45. Jegaskanda S, Weinfurter JT, Friedrich TC, Kent SJ. Antibody-dependent cellular cytotoxicity is associated with control of pandemic H1N1 influenza virus infection of macaques. $J$ Virol. (2013) 87:5512-22. doi: 10.1128/JVI.03030-12

46. Carroll TD, Jegaskanda S, Matzinger SR, Fritts L, McChesney MB, Kent SJ, et al. A Lipid/DNA adjuvant-inactivated influenza virus vaccine protects rhesus macaques From uncontrolled virus replication after heterosubtypic influenza a virus challenge. J Infect Dis. (2018) 218:856-67. doi: 10.1093/infdis/jiy238

47. McCarthy KR, Watanabe A, Kuraoka M, Do.KT, McGee. CE, Sempowski. GD, et al. Memory B cells that cross-react with group 1 and group 2 influenza a viruses are abundant in adult human repertoires article memory b cells that cross-react with group 1 and group 2 influenza a viruses are abundant in adult human repertoires. Immunity (2018) 48:174-83.e9. doi: 10.1016/j.immuni.2017.12.009

48. Lee J, Boutz DR, Chromikova V, Joyce MG, Vollmers C, Leung K, et al. Molecular-level analysis of the serum antibody repertoire in young adults before and after seasonal influenza vaccination. Nat Med. (2016) 22:1456-64. doi: $10.1038 / \mathrm{nm} .4224$

49. Furuya $Y$, Chan J, Regner M, Lobigs M, Koskinen A, Kok T, et al. Cytotoxic $\mathrm{T}$ cells are the predominant players providing cross-protective immunity induced by \{gamma\}-irradiated influenza A viruses. J Virol. (2010) 84:4212-21. doi: 10.1128/JVI.02508-09
50. Budimir N, Huckriede A, Meijerhof T, Boon L, Gostick E, Price DA, et al. Induction of heterosubtypic cross-protection against influenza by a whole inactivated virus vaccine: the role of viral membrane fusion activity. PLoS ONE (2012) 7:e30898. doi: 10.1371/journal.pone.00 30898

51. Laidlaw BJ, Decman V, Ali M-A a, Abt MC, Wolf AI, Monticelli $\mathrm{L}$, et al. Cooperativity between $\mathrm{CD}^{+} \mathrm{T}$ cells, non-neutralizing antibodies, and alveolar macrophages is important for heterosubtypic influenza virus immunity. PLoS Pathog. (2013) 9:e1003207. doi: 10.1371 /journal.ppat.1003207

52. Guo H, Topham DJ. Multiple distinct forms of $\mathrm{CD}^{+} \mathrm{T}$ cell cross-reactivity and specificities revealed after $2009 \mathrm{H} 1 \mathrm{~N} 1$ influenza a virus infection in mice. PLoS ONE (2012) 7:e46166. doi: 10.1371/journal.pone.0046166

53. Roberts AD, Woodland DL. Cutting edge: effector memory $\mathrm{CD} 8^{+} \mathrm{T}$ Cells Play a prominent role in recall responses to secondary viral infection in the lung. The J Immunol. (2004) 172:6533-7. doi: 10.4049/jimmunol.172. 11.6533

54. Sridhar S, Begom S, Bermingham A, Ziegler T, Roberts KL, Barclay WS, et al. Predominance of heterosubtypic IFN- $\gamma$-only-secreting effector memory T cells in pandemic H1N1 naive adults. Eur J Immunol. (2012) 42:2913-24. doi: 10.1002/eji.201242504

55. Roberts AD, Ely KH, Woodland DL. Differential contributions of central and effector memory T cells to recall responses. J Exp Med. (2005) 202:123-33. doi: $10.1084 /$ jem. 20050137

Conflict of Interest Statement: LB is an employee of the company Bioceros, Utrecht, The Netherlands.

The remaining authors declare that the research was conducted in the absence of any commercial or financial relationships that could be construed as a potential conflict of interest.

Copyright (๑ 2018 Dong, Bhide, Sicca, Meijerhof, Guilfoyle, Engelhardt, Boon, de Haan, Carnell, Temperton, de Vries-Idema, Kelvin and Huckriede. This is an openaccess article distributed under the terms of the Creative Commons Attribution License (CC BY). The use, distribution or reproduction in other forums is permitted, provided the original author(s) and the copyright owner(s) are credited and that the original publication in this journal is cited, in accordance with accepted academic practice. No use, distribution or reproduction is permitted which does not comply with these terms. 